\title{
An analytical solution for flow estimation of a meandering compound channel
}

\author{
Arpan Pradhan ${ }^{1, *}$ and Kishanjit Kumar Khatua ${ }^{2}$ \\ ${ }^{1}$ Ph.D. Candidate, Hydraulic Laboratory, NIT, Rourkela, India \\ ${ }^{2}$ Associate Professor,Department of Civil Engineering, NIT, Rourkela, India
}

\begin{abstract}
An analytical model is proposed to determine the discharge capacity in a meandering compound channel. The channel cross-section is divided into four sub-sections, such as the lower main channel, the floodplain within the meander belt and the two outer floodplains. Momentum transfer in-between these four subsections is taken into consideration in the analytical model. The model basically determines the force balance of each individual subsection to predict its mean velocity and thereby the sub-sectional discharge. The paper suggests a non-dimensional parameter, $\alpha_{T}$, which is the momentum transfer coefficient, that is determined to be unique for each individual channel. The paper deals with the calibration of this parameter for both largescale and small-scale data sets.
\end{abstract}

\section{Introduction}

Flow in a straight compound channel has both the main channel and the floodplain moving in the direction of the valley slope. Flow in the meandering compound channel is complicated, unlike straight compound channels, where the main channel progresses in the direction of the meandering pattern and the floodplain moves in the direction of the valley slope [1]. Contrary to straight compound channels, flow in meandering channels is different where water no longer flows primarily in the main channel or the valley direction with mixing restricted to the main channel and floodplain interface. Rather, a three dimensional interaction of water from floodplain to the main channel and vice-versa occurs [2]. For the case of meandering compound channels, in addition to the variation in velocity in the lower main channel and the upper floodplain region; flow in the outer floodplain region is also determined to be faster than that of the floodplain within the meander belt [3]. [1, 4, 5] also observed similar trends, for higher relative depths. [1] observed a uniform lateral velocity for lower relative depth of 0.15 ; for relative depth 0.5 , the highest velocity occurred at the center of the floodplain. [6] presented that, at low over-bank flow, the interaction of flow above and below bank cause a significant deflection above the bank-full level while at deeper over-bank flows the interaction is less significant and the two layers are less dependent on each other. The above observations demonstrate that the position of highest velocity and in turn

\footnotetext{
*e-mail: er.arpanpradhan@gmail.com
} 
the direction of momentum transfer depends on the relative depth of flow. These velocity differences amongst the subareas of a compound meandering channel causes shear stress along the interface planes. Therefore, besides the horizontal interface between lower main channel and the upper floodplain, vertical interface differentiating the meander belt width and the outer floodplains is also considered.

Taking into account these complicated flow interactions, different methods to predict stage-discharge has been presented [7-11], based on conventional channel division and classical Manning's equation approaches. Moderately a few two dimensional (2D) and three dimensional (3D) numerical approaches [5, 12-14] have also been developed which provide higher precision in discharge prediction for meandering channels. These models although favorable, are relatively complicated and require quite a few empirical constants such as dimensionless eddy viscosity, local friction factor, secondary flow etc. On the other hand, one dimensional (1D) methods are simple and convenient.

In this paper, an attempt is made in proposing a simple 1D method for assessing discharge capacity in compound meandering channels by considering only the momentum transfer between the subsections. The compound channel is considered to be divided into four subsections. Force balance relationship for each of the subsections is evaluated by considering the apparent shear forces at the interface planes. Zonal velocity at the subareas is determined to calculate zonal discharges and thereby the total discharge. The method is applied to the large-scale flood channel facility (FCF) experimentations and the small-scale channels of [15] and [16] to evaluate the momentum transfer coefficient in each of these channels. Procedure to calibrate the momentum transfer coefficient for a meandering compound channel from the measured discharge is proposed.

\section{Force balance among subsections}

Figures 1 and 2 illustrates the plan view and the cross-section of a typical meandering compound channel respectively. The total channel cross-section is divided into lower main channel (subsection 4), the floodplain within the meander belt (subsection 2) and the outer floodplains (subsections 1 and 3), [7-9, 17].

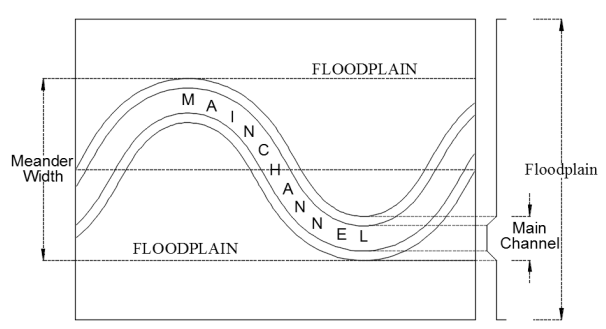

Figure 1. Plan of a meander wavelength

[8] used the channel division approach by [9] for the subsection assessment method for meandering compound channels which has been incorporated in this paper. [8] suggested that the longitudinal velocities below bank-full level tend to follow the main channel sidewalls while the floodplain velocities are generally in the valley direction. Therefore, a horizontal shear layer between the lower main channel and the floodplain is assumed to occur. [1] proposed a similar observation on account of [16, 18, 19]. 
Another important mechanism anticipated by $[8,9,20]$ is that the floodplain flow outside the meander belt is usually faster than within the belt suggesting that the meandering main channel has negligible effect on the outer floodplain. [1, 5] suggested that due to the existence of complex and strong momentum exchange at the interfaces, the mixing regions have to be separated. In addition, the flow behaviour in meandering compound channels observed by various researchers indicate that both the outer floodplain regions behave indistinguishably and independent of the flow over meander belt $[1,4,21]$, therefore having almost equivalent mean velocity. The above explanation thus substantiates the channel division assumed in this paper.

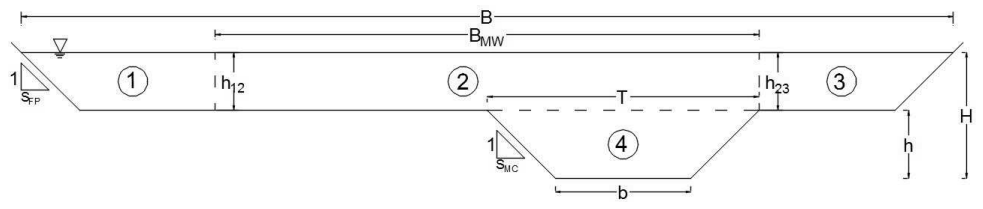

Figure 2. Cross-section of a Meandering Channel

In the present analytical model, for an initial formulation of force balance equations, the velocity at the meander belt region has been assumed to be higher than that of the outer floodplains and the lower main channel. The net rate of momentum flux into a control volume plus the sum of the gravitational and friction forces is equal to the rate of accumulated momentum within the control volume [22]. The flow over a wavelength $\left(L_{W}\right)$ of meandering channel is presumed to be quasi-uniform, for which energy loss observations were carried out by $[7,8]$. Hence, the shear force calculations for the force balance relationship in this paper is considered for a flow body over a wavelength, where the total gravitational component balances the sum of apparent shear forces and the bed shear force. The length travelled by the flow in the main channel is taken as sinuosity $(s)$ times the wavelength. The hydraulic slope for the lower main channel (subarea 4) and the meander belt region (subarea 2) is taken as $\left(S_{0} / s\right)$ as depicted by $[9,17]$ while the floodplain gradient $\left(S_{0}\right)$ is used in calculating the outer floodplain flows.

The force balance relationships can thus be expressed as follows; for the left outer floodplain (Subsection 1)

$$
\rho g A_{1} L_{W} S_{0}-P_{1} L_{W} \tau_{b 1}+h_{12} L_{W} \tau_{a 12}=0
$$

for the meander belt width region (Subsection 2)

$$
\rho g A_{2} L_{W} \frac{S_{0}}{s}-P_{2} L_{W} \tau_{b 2}-h_{12} L_{W} \tau_{a 12}-h_{23} L_{W} \tau_{a 23}-T\left(L_{W} s\right) \tau_{a 24}=0
$$

for the right outer floodplain (Subsection 3)

$$
\rho g A_{3} L_{W} S_{0}-P_{3} L_{W} \tau_{b 3}+h_{23} L_{W} \tau_{a 23}=0
$$

and for the lower main channel (Subsection 4)

$$
\rho g A_{4}\left(L_{W} s\right) \frac{S_{0}}{s}-P_{4}\left(L_{W} s\right) \tau_{b 4}+T\left(L_{W} s\right) \tau_{a 24}=0
$$

where, $\rho$ is the water density, $g$, the acceleration due to gravity, $S_{0}$ is the bed slope of floodplain and $s$ is the sinuosity of the meandering channel. $A_{i}$ and $P_{i}$ are the 
cross-sectional area and the wetted perimeter of the subarea $i$ respectively, excluding the division lines. $T$ is the width of the horizontal interface between the lower main channel and the meander belt width whereas $h_{12}$ and $h_{23}$ are the depths of vertical interface between the meander belt width and the left and right outer floodplains respectively. $\tau_{b i}$ is the boundary shear stress on the channel beds for the subareas. $\tau_{a 12}$ and $\tau_{a 23}$ are the mean apparent shear stresses on the vertical interfaces.

\section{Determination of Stresses}

\subsection{Sub-sectional Boundary Shear Stress}

Boundary shear stress is proportional to the square of the flow velocity for steady uniform flow. Assuming the condition appropriate for zonal boundary shear in compound channels, the boundary shear stress, $\tau_{b i}$, in subsection $i$ may be expressed as,

$$
\tau_{b i}=\frac{\rho g}{C_{i}^{2}} V_{i}^{2}
$$

where $C_{i}$ and $V_{i}$ are the Chezy coefficient and the mean velocity in the subsection $i$ $(1,2$ and 3$)$ respectively. $\rho g / C^{2}$ is the proportionality coefficient [23].

\subsection{Interface Stresses}

Horizontal shear layer between the faster moving water in the meander belt width and the slower moving lower main channel is formed, where vertical exchange of lateral momentum occurs. Consequently, vertical apparent shear exists at the interface of the meander belt region and the outer floodplain, which generally accelerate the flow in the outer floodplains and resists the flow in the meander belt width where the horizontal exchange of vertical momentum occurs.According to the momentum transfer theory of Prandtl [24], one assumes that the mean apparent shear stress on the horizontal interface between the upper and lower main channels, $\tau_{a 24}$, may be expressed in terms of the vertical gradient of characteristic velocity, $U_{a}$ as

$$
\tau_{a 24}=\rho \varepsilon_{24} \frac{\partial U_{a}}{\partial z}
$$

where $\varepsilon_{24}=$ turbulent eddy viscosity coefficient; and $z=$ vertical direction.

According to [25], the turbulent eddy viscosity is expressed as the product of a dimensionless coefficient, characteristic velocity $U_{a}$ and characteristic height in the horizontal shear region between the upper and lower main channel. Consequently, the horizontal apparent shear stress is expressed as,

$$
\tau_{a 24}=\alpha_{24} \rho \frac{V_{2}^{2}-V_{4}^{2}}{2}
$$

in which $\alpha_{24}$ is defined as the dimensionless horizontal momentum transfer coefficient. This can also be represented as $\alpha_{H}$. Using a similar approach, vertical apparent shear forces can be determined on the vertical interfaces [25]. By analogy,

$$
\tau_{a 12}=\alpha_{12} \rho \frac{V_{2}^{2}-V_{1}^{2}}{2}
$$


and

$$
\tau_{a 23}=\alpha_{23} \rho \frac{V_{2}^{2}-V_{3}^{2}}{2}
$$

where $\alpha_{12}$ and $\alpha_{23}$ are the momentum transfer coefficients on the corresponding vertical interfaces.

$[26,27]$ stated that for symmetrical channel cross-sections, the momentum transfer coefficients on the vertical interface between the upper main channel and the left and right floodplains are equal, i.e. $\alpha_{12}=\alpha_{23}$. Therefore, the vertical momentum transfer coefficient on each interface is designated as $\alpha_{V}$.

According to [28], as the floodplain width increases it increases the apparent shear force acting at the interface between the main channel and floodplains. This shows that the momentum transfer coefficient is dependent on the ratio of floodplain width to that of the main channel [25, 29-31].

Due to asymmetry in the cross-section of a meandering compound channel, the total vertical momentum transfer coefficient, $\left(2 \alpha_{V}\right)$ is presumed to be shared between the left and right interfaces in their respective ratios of floodplain to the total channel width. The vertical momentum transfer coefficients are hence represented as,

$$
\alpha_{12}=(\alpha+\alpha \chi-1) \frac{1}{\alpha} \alpha_{V}
$$

and

$$
\alpha_{12}=(\alpha-\alpha \chi+1) \frac{1}{\alpha} \alpha_{V}
$$

where $\alpha=B / b$ is the width ratio of the compound channel and $\chi=B_{M W} / B$ is the ratio of meander belt width to that of the overall floodplain width $(B), b$ here is main channel bed width.

Solving analytically Eqs. (1) to (4), the expression for the velocity in every subsection may be analytically found. Correspondingly, the sub-sectional discharge is also estimated.

\section{Experimental data sets}

The method is applied to conventionally recommended experimental data sets. The data sets used here, are the large scale Flood Channel Facility (FCF) Phase B experimentations conducted by HR Wallingford, UK [8]; the small scale experimentations by the [15] at the Waterways Experiment Station in Vicksburg, Mississippi, USA and the experimental study of [16]. The experimental observations used here along with the channel parameters are summarized in Table 1.

In the experimentations of FCF Phase B, four series of data sets, particularly, B21, B26, B39 and B47 have been chosen. These data sets provide a comprehensive difference between different channel types having dissimilar sinuosity and width ratios. Both the series B21 and B26 have a crossover angle of $60^{\circ}$, but the former is a trapezoidal channel while the latter has a natural cross-section.

Three data series of [15] i.e. XII, XIII and XIV have been considered here, having a width ratio, 8 with sinuosity of $1.57,1.4$ and 1.2 respectively.

[16] carried out experimentations on four sets of 1.09 sinuosity channels having width ratio 5.56. The data sets are represented as TS1 to TS4 in Table 1 where the main channel depth ratio $(\delta=b / h)$ is 5.5 with the bed slopes $\left(S_{0}\right)$ varying from 0.000675 to 0.00367 . 
Table 1. Data set of meandering compound channels

\begin{tabular}{lcccccccccc}
\hline Data Sets & & $h(\mathrm{~m})$ & $b(\mathrm{~m})$ & $B(\mathrm{~m})$ & $B_{M W}(\mathrm{~m})$ & $L_{W}(\mathrm{~m})$ & $s$ & $S_{0}$ & $\beta$ & $Q\left(\mathrm{~ms}^{-1}\right)$ \\
\hline & B21 (14) & 0.15 & 0.9 & 10 & 6.107 & 12 & 1.374 & 0.000996 & $0.080-0.480$ & $0.0975-0.9894$ \\
FCF Smooth & B26 (16) & 0.15 & 0.9 & 10 & 6.107 & 12 & 1.374 & 0.000996 & $0.017-0.490$ & $0.0399-1.0929$ \\
$(1990-1991)$ & B39 (14) & 0.15 & 0.9 & 10 & 8.56 & 10.31 & 2.043 & 0.001021 & $0.090-0.500$ & $0.0382-0.9435$ \\
& B47 (14) & 0.15 & 0.9 & 8.56 & 8.56 & 10.31 & 2.043 & 0.001021 & $0.090-0.490$ & $0.0356-0.7506$ \\
\hline US Army & XII (3) & 0.1524 & 0.6096 & 4.877 & 4.419 & 7.315 & 1.57 & 0.001 & $0.167-0.375$ & $0.0396-0.2231$ \\
Vicksburg & XIII (3) & 0.1524 & 0.6096 & 4.877 & 3.761 & 7.315 & 1.4 & 0.001 & $0.167-0.375$ & $0.0439-0.2429$ \\
$(1956)$ & XIV (3) & 0.1524 & 0.6096 & 4.877 & 2.822 & 7.315 & 1.2 & 0.001 & $0.167-0.375$ & $0.0484-0.2772$ \\
\hline & TS1 (5) & 0.0381 & 0.2094 & 1.185 & 0.462 & 1.28 & 1.09 & 0.000675 & $0.4010-0.5270$ & $0.0063-0.0126$ \\
Toebes and & TS2 (6) & 0.0381 & 0.2094 & 1.185 & 0.462 & 1.28 & 1.09 & 0.00087 & $0.3875-0.5261$ & $0.0063-0.0142$ \\
Sooky (1989) & TS3 (6) & 0.0381 & 0.2094 & 1.185 & 0.462 & 1.28 & 1.09 & 0.0016 & $0.3374-0.4700$ & $0.0063-0.0142$ \\
& TS4 (6) & 0.0381 & 0.2094 & 1.185 & 0.462 & 1.28 & 1.09 & 0.00367 & $0.3009-0.3924$ & $0.0063-0.0142$ \\
\hline
\end{tabular}

\section{Calibration of Momentum Transfer Coefficient}

Momentum transfer coefficient is a value, characterizing the intensity of momentum transfer in a compound channel [32]. The proposed model to estimate the discharge capacity of a meandering compound channel is verified by fixing different momentum transfer coefficient values for the interfaces in series B21 of FCF before applying to other data sets.

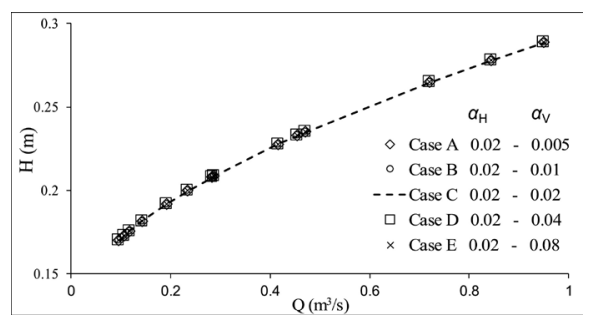

Figure 3. Effect of $\alpha_{T}$ on discharge of FCF series B21

Five cases are considered here, i.e. cases A to E where the horizontal momentum transfer coefficient, $\alpha_{V}$ is fixed at a value of 0.02 . For case $\mathrm{C}$, the vertical and horizontal transfer coefficients are assumed to be same i.e. $\alpha_{V}=\alpha_{H}=0.02$. Cases A and B have $\alpha_{H}$ values as one-fourth and one-half of $\alpha_{V}$ whereas case $\mathrm{D}$ and $\mathrm{E}$ have $\alpha_{H}$ values as twice and four times of $\alpha_{V}$. The result for the stage-discharge computation for these cases is depicted in Figure 3 where the discharge capacity is observed to be invariable, implying that the momentum transfer coefficient can be taken as the same value for both the vertical and horizontal interfaces. Hence, in the application of the method, $\alpha_{V}$ and $\alpha_{H}$ are replaced as $\alpha_{T}$, the momentum transfer coefficient.

The variation of the mean relative error $\bar{\varepsilon}_{r}$, for all the respective experimental data sets is studied, with different values of $\alpha_{T}$. The mean relative error is defined as the absolute value of the ratio between the difference of computed and measured discharge to the measured, which is expressed as,

$$
\bar{\varepsilon}_{r}=\left|\frac{Q_{c}-Q_{m}}{Q_{m}}\right| 100 \%
$$


This calibration technique can be utilized to obtain an unique momentum transfer coefficient for a meandering channel with measured stage-discharge data.
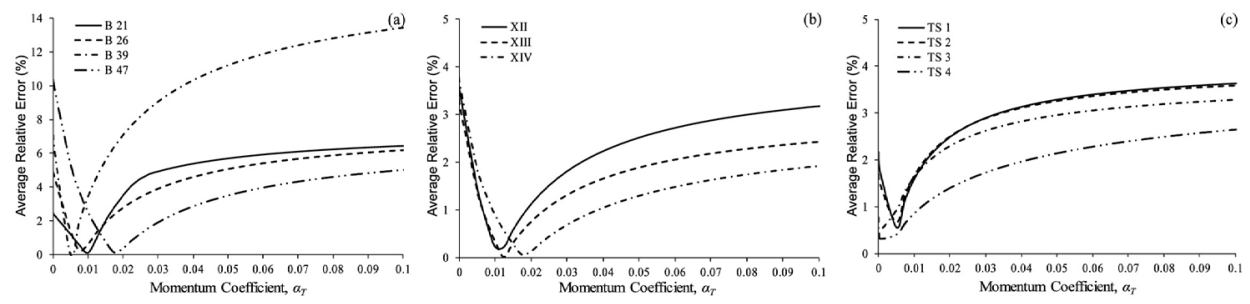

Figure 4. Variation of $\bar{\varepsilon}_{r}$ with $\alpha_{T}$ for laboratory data sets

Figure 4 illustrates the variation of mean relative error in different data sets of FCF Phase B, [15] and [16] for varying values of $\alpha_{T}$. As observed in all the insets (a), (b) and (c), although $\alpha_{T}$ varies in-between 0.005 to 0.02 , an average value of 0.01 can be taken as a standard value of $\alpha_{T}$. A value of 0.01 for $\alpha_{T}$, provides mean relative error of around $1 \%$ in the FCF Channels while providing less than $0.5 \%$ and around $1.5 \%$ in [15] and [16] respectively. Therefore, taking into account the data ranges in the study, it is presumably acceptable to consider 0.01 as the momentum transfer coefficient in meandering compound channels for the present ranges of data.

\section{Conclusion}

The vertical momentum transfer between the lower main channel and meander belt width and also the lateral momentum transfer between the meander belt width and the outer floodplains have been considered. With respect to other conventional divided channel methods, the proposed model is quite effective as it takes into account the apparent shear forces at the interfaces of adjoining subareas. The average relative error in the stage-discharge predictions has been carried out, not only for the large scale channels of FCF, but also the small scale channels of [15] and [16]. The present model is quite simple with regard to the other $2 \mathrm{D}$ and $3 \mathrm{D}$ methods for discharge estimation. The proposed model takes into account only one parameter, i.e. the momentum transfer coefficient, which needs to be calibrated for different data sets. It has been concluded in the study that the momentum transfer coefficient for different interfaces in a compound meandering channel are the same and also that it remains relatively constant for different flow depths. For the present ranges of data sets, it has been substantiated that a value of 0.01 as $\alpha_{T}$, provides acceptable error in the discharge predictions. For data sets beyond these ranges, the value can be calibrated by the measured stage discharge data as illustrated in this paper.

\section{References}

[1] K. Shiono, Y. Muto, Journal of Fluid Mechanics 376, 221 (1998)

[2] B.B. Willetts, R.I. Hardwick, Proceedings of the Institution of Civil EngineersWater Maritime and Energy 101, 45 (1993)

[3] C.S. James, Journal of Hydraulic Engineering 120, 245 (1994)

[4] K. Shiono, T.L. Chan, J. Spooner, P. Rameshwaran, J.H. Chandler, Journal of Hydraulic Research 47, 5 (2009) 
[5] C. Liu, N. Wright, X. Liu, K. Yang, Advances in Water Resources 74, 26 (2014)

[6] J. Spooner, K. Shiono, Proceedings of the Institution of Civil Engineers-Water and Maritime Engineering 156, 225 (2003)

[7] D.A. Ervine, J. Ellis, Earth and Environmental Science Transactions of The Royal Society of Edinburgh 78, 315 (1987)

[8] C.S. James, J.B. Wark, Report SR-329, HR Wallingford Ltd (1992)

[9] R.K. Greenhill, R.H.J. Sellin, Proceedings of the Institution of Civil EngineersWater Maritime and Energy 101, 37 (1993)

[10] K. Shiono, J.S. Al-Romaih, D.W. Knight, Journal of Hydraulic Engineering 125, 66 (1999)

[11] K.C. Patra, S.K. Kar, Journal of Hydraulic Engineering 126, 593 (2000)

[12] H. Jing, Y. Guo, C. Li, J. Zhang, International Journal for Numerical Methods in Fluids 59, 927 (2009)

[13] H. Morvan, G. Pender, N.G. Wright, D.A. Ervine, Journal of Hydraulic Engineering 128, 674 (2002)

[14] D. Xu, C. Ji, Y. Bai, X. Song, Journal of Hydroinformatics 19, 666 (2017)

[15] C.o.E. U S Army, Technical Memorandum 2-429, U.S. Waterways Experiment Station, Vicksburg, Mississippi (1956)

[16] G.H. Toebes, A.A. Sooky, Journal of the Waterways and Harbors Division 93, $213(1967)$

[17] J.J. O'Sullivan, W.R.C. Myers, J.F. Lyness, M.F. Lambert, Proceedings of the ICE - Water and Maritime Engineering 156, 313 (2003)

[18] R.H.J. Sellin, D.A. Ervine, B.B. Willetts, Proceedings of the Institution of Civil Engineers-Water Maritime and Energy 101, 99 (1993)

[19] G.K. Kiely, Ph.D. thesis, University College Cork, Ireland (1989)

[20] A.B. MacLeod, Ph.D. thesis, University of Glasgow, Scotland, UK (1997)

[21] C. Liu, Y. Shan, X. Liu, K. Yang, Proceedings of the Institution of Civil Engineers-Water Management 169, 17 (2015)

[22] D. Bousmar, Y. Zech, Journal of Hydraulic Engineering 125, 696 (1999)

[23] V.T. Chow, Open channel hydraulics (McGraw-Hill, New York, 1959)

[24] H. Schlichting, K. Gersten, Boundary Layer Theory (Berlin: Springer, 2000)

[25] K. Yang, X. Liu, S. Cao, E. Huang, Journal of Hydraulic Engineering 140 (2013)

[26] F. Huthoff, P.C. Roos, D.C. Augustijn, S.J. Hulscher, Journal of Hydraulic Engineering 134, 1158 (2008)

[27] Z. Yang, W. Gao, W. Huai, Journal of Hydraulic Research 50, 105 (2012)

[28] P.R. Wormleaton, in Coherent flow structures in open channels (Wiley: Chichester, 1996), pp. 581-608

[29] G.C. Noutsopoulos, G.C. Christodoulou, Journal of Hydraulic Engineering 111, $884(1985)$

[30] G.C. Christodoulou, Water Resources Management 6, 235 (1992)

[31] P.J. Moreta, J.P. Martin-Vide, Journal of Hydraulic Research 48, 169 (2010)

[32] S.Q. Yang, S.K. Tan, X.K. Wang, Journal of Geophysical Research: Earth Surface 117 (2012) 